\title{
Presentism/Eternalism and Endurantism/Perdurantism: why the unsubstantiality of the first debate implies that of the second ${ }^{1}$
}

\author{
Forthcoming in Philosophia Naturalis
}

\author{
Mauro Dorato (Ph.D) \\ Department of Philosophy \\ University of Rome Three \\ dorato@uniroma3.it \\ tel. +393396070133 \\ http://host.uniroma3.it/dipartimenti/filosofia/personale/doratoweb.htm
}

\begin{abstract}
The main claim that I want to defend in this paper is that the there are logical equivalences between eternalism and perdurantism on the one hand and presentism and endurantism on the other. By "logical equivalence" I mean that one position is entailed and entails the other. As a consequence of this equivalence, it becomes important to inquire into the question whether the dispute between endurantists and perdurantists is authentic, given that Savitt (2006) Dolev (2006) and Dorato (2006) have cast doubts on the fact that the debate between presentism and eternalism is about "what there is". In this respect, I will conclude that also the debate about persistence in time has no ontological consequences, in the sense that there is no real ontological disagreement between the two allegedly opposite positions: as in the case of the presentism/eternalism debate, one can be both a perdurantist and an endurantist, depending on which linguistic framework is preferred.
\end{abstract}

The main claim that I want to defend in this paper is that the there are logical equivalences between eternalism and perdurantism on the one hand and presentism and endurantism on the other. By "logical equivalence” I mean that one position is entailed and entails the other. As a consequence of this equivalence, it becomes important to inquire into the question whether the dispute between endurantists and perdurantists is authentic, given that Savitt (2006) Dolev (2006) and Dorato (2006) have cast doubts on the fact that the debate between presentism and eternalism is about "what there is". In this respect, I will conclude that also the debate about persistence in time has no ontological consequences, in the sense that there is no real ontological disagreement between the two allegedly opposite positions: as

\footnotetext{
${ }^{1}$ My thanks to Florian Fischer, Cord Friebe, Thomas Müller and Thorben Petersen for their valuable comments and criticism concerning a previous version of this paper. All remaining errors are my responsibility.
} 
in the case of the presentism/eternalism debate, one can be both a perdurantist and an endurantist, depending on which linguistic framework is preferred.

More in detail, I will defend the following equivalence: in the case of the presentism/eternalism debate, present-tense expressions have the aim of expressing the temporal position of the speaker vis à vis the events one is referring to; but in other circumstances, by using a tenseless copula, one is taking a sort of an non-perspectival, viewfrom-nowhere outlook vis à vis past, present and future events, by declaring them to be all tenselessly coexistent. Both uses of the copula (tensed and tenseless) are consistent and important, so that there is no reason to transform the choice of a language into a philosophical dispute about what there is. Analogous conclusion will be show to hold for the endurantist/perdurantism dispute.

In particular, in section 1 of the paper I will defend the above mentioned equivalence, while in section 2 I will show in what sense, in virtue of the equivalence, one could argue that if presentism/eternalism is a pseudo-debate on the ontological level, because both a presentist and an eternalist language are appropriate in different circumstances, then so is the endurantist/perdurantist issue. In section 3, finally, I will argue that the issue of persistence in time, exactly as that between presentism and eternalism, makes a very superficial use of physics: philosophers try to use the prestige of the latter in order to give some substance to purely a priori debates, a philosophical approach which runs the risk of creating a new scholastics. Such an irrelevance is, I take it, an independent argument against the importance of the metaphysical debate about persistence in time, not because metaphysics should not pursue investigations in issues that science cannot settle, but because the use of physics in the debate in question is external and superimposed. 


\section{A chain of logical equivalences}

Just to fix terminology, in the remainder of this paper I will assume that eternalism is committed to the tenseless coexistence of all events, while presentism is committed to the thesis that existence is confined just to the present events, while future and past events do not exist. In order to show the logical equivalences mentioned above, I will take perdurantism as the doctrine that all entities persist in time by having temporal parts, while endurantism will be regarded as the doctrine that all entities have no temporal parts, so that they all persist in time by being "wholly present” when they exist.

Two important remarks are appropriate before entering in medias res. 1) I presented endurantism as the negation of perdurantism: whether a third alternative to these two doctrines is available is an interesting question that here will not be discussed. 2) The presentist/eternalist debate is often formulated as involving only events, while the issue of persistence in time is typically taken to concern only things. In the definition above I considered "entity" as a general term that applies to both things and events. This terminological choice, however, needs some justification. On the one hand, admittedly, if events and things were two irreducible ontic categories, we would have prima facie evidence against the possibility of using the above mentioned equivalence to shed light on the meaningfulness of the endurantist/perdurantism debate. On the other hand, however, if, at least at the beginning, we leave the issue of the ontic dualism about entities and things open, and if the equivalence I am after is correct, as I think it is, two possible consequence could result, neither of which need to be tackled here:

(i) either also talk of things and talk of events ends up being intertranslatable, so that events and things ought not to be regarded as individuating two different ontological 
categories,

(ii) or there are two different ways in which individual entities persist in time, things by enduring and events by perduring, so that perdurantism and endurantism are both true, in a sense not altogether different from that in which, in my opinion, presentism and eternalism are both true in different circumstances.

In the former option (i), the pluralistic claim that some entities (things) persist by enduring and others (events) persist by perduring would have to be abandoned, and my final claim will be independently motivated by the ontological equivalence of those entities that are typically regarded as perduring (events) and those that are typically regarded as enduring (things). In the latter alternative (ii), pluralism would turn out be the right way of interpreting the debate, ${ }^{2}$ but in this case the interest of the debate, which in the formulation above I took to be about all persisting entities, would be deflated in the direction that here is argued for and defended.

1.1 How to prove that endurantism entails presentism ${ }^{3}$

Let me label endurantism as defined above with "END” and presentism with "PRES"; ETER stands for eternalism and PER for perdurantism. In this section I will show that END $\rightarrow$ PRES. Assume endurantism: it follows that entities have no temporal parts (this feature, I have assumed, is essential to endurantism). If entities have no temporal parts, then:

1) they are 3-dimensional;

2) they possess only spatial parts;

3) They exist wholly at each moment in which they exist.

Let us focus on condition 3), and on the current debate whether in general "exist" is or is not

\footnotetext{
${ }^{2}$ Such a pluralism is defended in Mellor (1981).

${ }^{3}$ For papers connecting the persistence debate with presentism and eternalism, see Merricks (1995 and 1999), and Rea (1998)
} 
ambiguous between tensed and tenseless existence. In temporal contexts one can always raise the question whether "exist" is meant in the tensed or in the tenseless sense of existence, so that existence in 3) is indeed ambiguous. If entities exist wholly at each moment of their existence, then:

(a) Entities can either exist only in the present (presentism), or

(b) There are (tenselessly coexisting) moments in the past and in the future, at each of which entities wholly exist (eternalism); if both of these linguistic ${ }^{4}$ options were compatible with endurantism - that is, if (END \& PRES) and (END \& ETER) were both true - my claim that presentism is derivable from endurantism would be false.

However, I will now show that my claim is not false. If (a) is the case, the sought-after implication (endurantism $\rightarrow$ presentism, or END $\rightarrow$ PRES) is proven. If (b) is the case, the tenseless coexistence of moments of past and future times at each of which the same entity wholly exist seems to drive us toward the existence of "durationless" temporal parts of the entity, against our assumption of END.

To understand why this conclusion follows, assume per absurdum that endurantism be compatible with eternalism (END \& ETER) and consider two "things" at a certain time, for instance, "me at the present moment", or "the Mount Everest at the present moment". By endurantist hypothesis, both I and the Mount Everest now have no temporal parts and now exist wholly (whatever that means, see infra). "Me-at-past-time-t" and "me-at-future-time-t”, however, also don't have temporal parts, but, on the assumption that eternalism be consistent with endurantism, they would tenselessly coexist with me-now. Given such a tenseless coexistence, however, "I" might end up being constituted by my complete history or by the totality of my different temporal parts (past, present and future "stages"). Each of these stages

\footnotetext{
${ }^{4}$ Here "linguistic" is important, since it serves to signal that the distinction between presentism and eternalism concerns two different ways of reading existence, both admissible and useful, and not ontology, since in different linguistic contexts we talk like a presentist and in others like an eternalist. I am not assuming that presentist talk is translatable into eternalist talk.
} 
would have no temporal parts because they can be regarded as having no temporal duration. Since by assuming endurantism we assumed lack of temporal parts, but eternalism entails the existence of tenselessly coexisting temporal parts, if I (a prima facie "thing”) am constituted by, or identical with, my history (prima facie “events”), we are forced to accept that also on hypothesis (b) endurantism $\rightarrow$ presentism (END $\rightarrow$ PRES).

One could object that an indexing of entities to (proper) time or (coordinate) time, i.e., descriptions of the sort "me at the present moment", ought to be banned by endurantists and are therefore question-begging. One cannot "relativize" to time entities which, by hypothesis, have no temporal parts: that is, it could be objected that for the endurantist there are no such things as "me-now" or "my future-self”, but only me, existing wholly by being multilocated at different regions of spacetime. However, it is not clear why "me (or my body) at t", or "Mount Everest at t" should be unconceivable or banned in an endurantistic language, since also endurantists must be able to consider the existence of enduring entities at certain instants of time. Endurantists could of course admit the necessity of using our language in this way, but claim at the same time that such a use is referentially empty, thereby assigning a purely instrumental value to the time-indexing of Mount Everest or of me. But the claim "Mount Everest in 1911 was devoid of human traces, while Mount Everest in 2011 is full of them” is certainly true, and the truth makers of this assertion can be regarded either (a) as different, tenselessly coexisting temporal parts or slices of the selfsame persisting entity or (b) as two different properties instantiated by the same thing/substance at different times. In the former hypothesis (a), the endurantist that embraces eternalism must embrace the tenseless coexistence of temporal parts of Mount Everest, and therefore abandon her view that things have no temporal parts. So END entails PRES, as wanted.

In the second hypothesis (b), the eternalist endurantist must concede that different properties exemplified by the same substance at two different times-places are different events 
(this is Kim's 1976 view of events). Such events, by occurring to the very same substance and by happening at different times, must be regarded as tenselessly coexistent (in virtue of eternalism). But if these events coexist tenselessly, nothing prevents one from arguing that they can be regarded as different temporal parts of the same mountain, so that there is nothing over and above the mountain than its full history, that is, the set of all events that occur to it. The typical monistic argument against the independent existence of substances (or things) runs in fact as follows: what is, after all, this empirically undetectable substance to which all attributes or properties would inhere if not a projection of the subject-predicate structure of our language onto reality that need not be mirrored by the structure of entities? ${ }^{5}$ While of course the discussion on this issue could and should continue, I will stop it here, since my purpose is not to solve the debate on the independent existent of things vis à vis that of events, but rather only to show that alternative characterizations of things/substances in terms of events are always possible. And this is enough to conclude that since eternalism implies the existence of temporal parts and we started by assuming endurantism, we are able to conclude that endurantism $\rightarrow$ presentism also on reading (b) of 3) above, which, it will be recalled, is the feature of enduring entities such that "they exists wholly at each times in which they exist”.

Summarizing the whole argument developed in this section, if endurantism (END) were first assumed and then regarded as consistent with eternalism (ETER), we would have a contradiction, because eternalism implies the existence of temporal parts for all entities (things or events). It follows that eternalism cannot be compatible with END. In symbols: $\neg(\mathrm{END} \& \mathrm{ETER}) \rightarrow(\mathrm{END} \rightarrow \neg \mathrm{ETER}) \rightarrow(\mathrm{END} \rightarrow \mathrm{PRES})$

\footnotetext{
${ }^{5}$ It could be maintained that the relation between a substance and its time-indexed properties (events) is no more mysterious than the relation between a perduring, temporally extended event and its non time-indexed properties. An exciting party (an entity with temporal parts) need not have this non-time indexed property ("being exciting”) at all times in which it exists, but it certainly must instantiate it at various stages of the party. There is nothing mysterious in this. On the contrary, a substance without events occurring to it at all times in which it exists, i.e., a substance without time-indexed properties, would be a mere nothing, in the same sense in which an abstract temporal part without properties would be nothing at all.
} 
1.2 Why also presentism entails endurantism (PRES $\rightarrow$ END)

Suppose that there is a way to formulate presentism in a non-trivial fashion, so that presentism does not oscillate between a tensed triviality (“all that exists now exists now”) and a tenseless contradiction ("whatever existed in the past or exists now or will exist in the future does not tenselessly exist, that is, it has not existed nor does it exist now nor will it exist”). ${ }^{6}$ Prima facie, if whatever exists exists now (as presentism has it), so that all that exists coexist in the same spatial hypersurface, then there are - in some very general sense of "there are”, if, controversially, there is such a general, unique existential quantification as Sider (2001) has it - no past or future parts of entities. To the extent that it makes sense to claim, along with presentists, that there are no past or future parts of entities, then there are also no temporal parts of them (endurantism). If presentism has a genuine linguistic formulation, then also the conclusion presentism $\rightarrow$ endurantism follows (PRES $\rightarrow$ ETER).

My point here is that we cannot conclude from the fact that presentism is neither a triviality nor a contradiction that there is a genuine ontological divide between presentism and eternalism, and it is this latter thesis that I deny, since the two different ways of looking at events in time (perspectivally as in presentism and non-perspectivally as in eternalism) do not exclude each other at all, and are both useful and important in different contexts. ${ }^{7}$

An objection against the claim that presentism entails endurantism springs to mind

\footnotetext{
${ }^{6}$ The contradiction is generated by reading the copula "is" in the statement of presentism - "the future event $E$ is unreal”- as a tenseless "is", amounting to "was, is now, or will be the case”. So my (future) death is unreal would mean that "it did not take place, it is not taking place now, nor will it take place", which is clearly false, because it will take place, something that also the presentist will concede, of course. On the other hand, "the future event $E$ is now (tensed copula) not real” is clearly trivially true, because what will occur (the future event $E$ ) is not occurring now! (I assume here that the truth-condition of utterance $U=$ "event $E$ is now not real" is given by the tenseless statement "E does not occur simultaneous with U", even though this truth condition and U mean different things).

${ }^{7}$ See Dolev (2006), Dorato (2006), and Savitt (2006), quoted above, that in different ways argue in favor of the dissolution of the presentist/eternalist debate at an ontic level. See also Dorato (2006a) for a corresponding deflationary thesis on absolute becoming and its apriori character, presupposed by all spacetime theories relying on an ontology of events.
} 
naturally, and involves transtemporal identity: one could ask whether (i) the now-existing entity $e$ will exist also in the future by preserving its identity, or (ii) e-now is a temporal part of a temporally extended entity $E$, which will have another part $e^{\prime}$ in the future, where $e \neq e^{\prime}$. In the former case (i), the now-existing entity endures because it preserves its identity at different times (and my thesis is proved), in the latter case (ii), however, there will exist a different part of $E$ at a future time (perdurantism), so that presentism and perdurantism, against my claim, seem to be wholly compatible.

In order to meet this objection, let us suppose per absurdum that presentism and perdurantism be compatible. ${ }^{8}$ Perdurantism requires the existence of a relation of "parthood" ( $x$ and $y$ are parts of $E$ ) among the temporal parts of any temporally extended, persisting entity, so that the presentist's claim that only the present part exists is more than seriously threatened. The fact is that the parts of a temporally extended entity $E$ can be related (i.e., the parts or stages can instantiate a relation of parthood) - as required by perdurantism- only if their relata all coexist tenselessly, as eternalists have it. Relations can exist only if their relata do. Since perdurantism entails eternalism but we started by assuming presentism, we have derived a contradiction; so we'd better conclude that presentism entails endurantism. ${ }^{9}$

On the assumption that presentism and endurantism are equivalent or imply each other, the same holds for eternalism and perdurantism, at least if $\neg$ eternalism $=$ presentism (no growing block view of reality, where only the future is unreal) and $\neg$ endurantism $=$ perdurantism. In order to further convince ourselves of the equivalence of these views, however, it is instructive to look into the converse implications, involving endurantism and

\footnotetext{
${ }^{8}$ Brogaard (2000) is a defense of a fourdimensionalist type of presentism, that is, of the idea that a presentist can believe in temporal parts and therefore in perdurantism. See also Miller (2009).

${ }^{9}$ Another possible view on the matter is that presentists cannot have any theory of persistence, since reality is constituted by instantaneous slices (the nows) which succeed one another without either enduring or perduring. However, if I am a presentist, I would want to persist in time, in such a way that either my present stage be causally connected with my future stages (perdurantism), or in such a way that I endure in time by keeping my identity across my life. So presentism without some form of persistence in time is only compatible with a radical form of occasionalistic metaphysics, in which the world is created anew at each instant of time, and identity is merely illusory.
} 
eternalism.

1.2 Why eternalism entails perdurantism (ETER $\rightarrow$ PERD)

Assume eternalism. If all entities coexist in a tenseless sense (as eternalism preaches), any entity having more than an instantaneous existence has either (i) different temporal parts at different times and therefore perdures, or (ii) persists by enduring, that is, by existing wholly at each instants in which it exists. Since (i) proves my case, let us consider (ii), i.e., the possibility that the selfsame entity $E$ persists at two different times $t_{1}$ and $t_{2}$ by "existing wholly” at each of these times (endurantism), without having temporal parts.

Now the thorny question arises: what does "existing wholly" mean in this case, other than the fact that $E$ has no temporal parts? There is an important sense in which $E$ does not exist wholly at $t_{1}$, since the very same enduring $E$ also exists at $t_{2}$. This follows because it is always possible to treat $E$ at $\mathrm{t}_{1}$ and $E$ at $\mathrm{t}_{2}$ as two different stages or temporal parts of the very same $E$. In full analogy, in the theory of universals there is a sense in which if there are two different instantiations of the very same property $P, P$ does not exist fully in any of these instances, because the very same P can be regarded as the disjoint sum of all its instantiations in spacetime. It exists fully in all of its instances in the sense that it is identical with itself (the same P) in all of its instances.

Going back to our business, it is because we need a relation of genidentity for different stages of the same temporally extended event that eternalism entails the existence of temporal parts and therefore perdurantism (ETER $\rightarrow$ PERD). If it were not possible to identify at different times the same entity, the eternalist would have no way to claim that two stages or slices are indeed stages or slices of the same entity, and this is essential in any metaphysical doctrine of persistence through time. 
But even if this re-identification were not possible, and if worries about bare particulars as carriers of identity could be dispensed, so that an entity could be regarded as something over and above the set of events that occur to it at a given time, one could press the following, additional point. "Existing wholly at each moment of its existence" might mean that " $E$ is wholly present at each of these moments” in the temporal sense, which in turns is possible if and only if $E$ has no future or past parts at each moment in which it exists. This formulation of endurantism, however, pushes energically toward presentism: “ $E$ is wholly present at $t$ ” ends up meaning that "for all instants $t, E$ exists just when $t=$ now", which is a non-standard way of formulating presentism, but presentism nonetheless. However, (i) we assumed eternalism; (ii) the assumption of compatibility between eternalism and endurantism leads to presentism; in order to avoid a contradiction, we must conclude that eternalism entails perdurantism $($ ETER $\rightarrow$ PERD).

The argument in favor of the implication of eternalism by perdurantism is much easier to establish and has already been given: the relation of parthood among parts of temporally extended entities required by perdurantism ( " $x$ and $y$ are temporal part of $E$ ”) implies the tenseless coexistence of the temporal parts, and therefore eternalism; the implication from perdurantism to eternalism is therefore secured (PERD $\rightarrow$ ETER).

2 The consequences of the logical equivalence

If endurantism is logically equivalent to presentism, and perdurantism to eternalism, and if the presentism/eternalism is not a genuine ontological debate (as Savitt, Dolev, and Dorato have it, see above), it could be maintained that the endurantism-perdurantism debate comes out as non-genuine too: not because the latter two positions are intertranslatable (Miller 2005), but because endurantism and perdurantism are, respectively, logically equivalent to 
two ontologically compatible positions.

How plausible is this conclusion? It is important to understand the way in which presentism and eternalism can coexist, despite the fact that they seem to advocate ontologically distinct positions. Suppose that, qua presentist, I want to claim that only what is presently existing exists. Independently of the difficulty of determining what counts as present within a given different spacetime (a single pointlike event, a hypersurface of simultaneity, the null cone, the spacelike-related region to a point, etc.), ${ }^{10}$ there is no reason why a presentist should not accept that some events will exist (if now is not the last moment of time, or Big Crunch) and other events have existed (if now is not the first moment of time, or Big Bang). ${ }^{11}$ However, this is exactly what a reasonable eternalist should advocate. At least if we construe eternalism as the doctrine that any two entities coexist tenselessly if and only if they are part of the same spacetime, or if and only if one of the two entities will exist relative to the other, or both exist simultaneously, or one has existed relative to the other, where the past or the future tense is determined with respect to some instant of proper (STR) ${ }^{12}$ or cosmic time (GTR). In other words, there is no reason why an eternalist should not accept that inside a four-dimensional space-time, and relative to a given event, some events will exist and other have existed, as the presentist wants, modulo reference to local or global proper time depending on the spacetime we want to consider. So where is the ontological difference between the two positions? While for the defense of this version of eternalism I refer the reader to the previously mentioned papers, here it will suffice to say that a future or a past event do not now exist also for an eternalist, given that they will exist and have existed. Independently of questions related to what form the truth conditions of tensed sentences

\footnotetext{
${ }^{10}$ See Savitt (2000).

${ }^{11}$ A presentist might object that referring to the first or last moment of time makes reference to B time, as for a presentist the beginning (end) of time is the beginning (end) of the present. (I owe this objection to Cord Friebe). However, a presentist must be able to describe a cosmology in which the Universe has a finite duration in time and began 14,6 billions years ago. That is, it must be able to refer to the existence of past entities in some sense. Difficulties to have truth-conditions for non-present tense sentences must, and can be, overcome.

${ }^{12}$ Temporal succession is not annihilated even in Minkowski spacetime: it becomes local.
} 
should take, once the tensed and tenseless form of existence or of the copula are carefully separated, very little discussion remains, since the choice of one rather than of the other form of the copula boils down to a pragmatic question. Sometimes (very often and I daresay in most cases) we need to distinguish what exists now from what exists elsewhen (and then we use the tensed copula). Some other times, however, especially when we write physical theories or when we need to mark out the concrete existence in spacetime from fictional existence, we use the tenseless copula, by referring to whole set of concrete events located somewhere in spacetime.

In a word, the argument against the ontological significance of the debate on how entities persist in time is as follows. Given the logical equivalence defended above, it would seem that if the perdurantists/endurantists debate has to have ontic significance, it must have ontic significance also the presentist/eternalist debate. ${ }^{13}$ But since on the basis of previous work we are here assuming that the latter debate need not amount to a disagreement about ontology, the former debate also amounts to two different ways of describing persistence in time, with no ontological implications. ${ }^{14}$

If this is correct, we need to answer the following question: why does it look like that there is genuine ontological dispute between perdurantists and endurantists? The origin of the dispute lies, at least in part, in the fact that some entities change much more slowly than others. The slowly changing Mount Everest looks like an entity whose existence is "wholly present” at each moment in which it exists, so that its identity seems to remain unchanged across time: it looks as if there are no past or future parts of mountains! A concert, on the other hand, is a process having quick changes, so that it looks as if it has temporal parts that succeed one another. However, depending on our descriptive aims, Mount Everest can be

\footnotetext{
${ }^{13}$ For the purpose of the paper, one side of the biconditional suffice for the argument, namely for the thesis that perdurantism entails eternalism and endurantism entails presentism.

${ }^{14}$ Of course the implication could be used in the converse form: if the presentist/eternalist debate had an ontological character, also the perdurantist/endurantist debate would!
} 
regarded as a set of temporal parts (say, a geologist can be interested in the early stage of the formation of the mountain), and at the same time a whole concert can be regarded as having a trans-temporal identity in virtue of relations of genidentity or of the region it occupies in spacetime, while its temporal slices, when they exist, exist wholly simply because they are durationless.

Of course, a friend of the distinction perdurantism/endurantism would object that one can imagine a balloon (a purported substance which persists by enduring) quickly changing by deflating or inflating: these are events which occur to the enduring balloon, which however persist in time in a way that differs from the way in which its inflation or deflation persist. While one can of course choose this way of speaking, it is not clear what its ontological consequences are. In fact, what remains of the balloon after we consider all the events that take place "in" (?) it at a given moment of time? What sort of non-empirical heacceity remains after we remove all the time-indexed properties (events) from an object? Such an heacceity is certainly not a qualitative property on a par with the others, and it is doubtful whether it exists. On the other hand, if we consider a thunderstorm, such a paradigmatically perduring entity also has an identity to which we are typically less interested. However, if need arises, we can trace such an identity either to the event's spatiotemporal location, or to its properties, or to its causes and effects, or to whatever it is that we consider relevant in a given circumstance. In any case, in these cases the problem involves the identity of an entity more than the way in which it persists in time, even though the two questions are related.

3 Against a superficial use of physics: the argument from irrelevance

Even if all I wrote so far were wrong, it is important to remind ourselves that physics does not aim at establishing whether entities persist in time by perduring or enduring. This is 
not a problem that physicists are currently after. So no deep interactions between physics and metaphysics on the basis of the metaphysical dispute we are discussing seem forthcoming. I don't know of a possible development of physics that might render the current discussion about persistence in time relevant for a deeper understanding of the implication of the physics of time. Four-dimensionalism can be used to explain relativistic effects structurally, and reference to the present stage of expansion via cosmic time (a three-dimensional outlook) is also important for pragmatic reasons, as when we claim that the universe is now 14.6 billion years old. These pragmatic differences, however, do not seem to amount to an ontological divide between three-dimensionalism and four-dimensionalism. Even though in certain circumstances one way of speaking is preferred to another, attributing this pragmatic difference an ontological significance does not make any difference in our understanding current physical theories.

It could be objected that the aim of the metaphysics of time is not to contribute to a deeper understanding of time in physics. Rather, the idea is that one develops a metaphysical theory of persistence and then judges its plausibility in terms of logical and empirical consistency. "Empirical consistency" means, typically, that physics is used to adjudicate a metaphysical debate by eliminating or weakening one of the two contenders via compatibility arguments. However, certain philosophical discussions based on compatibility arguments tend to forget that physics underdetermines many metaphysical debates. Underdetermination seems to strike metaphysical disputes about three or four dimensionalism, or presentism and eternalism. It is always possible to introduce - for purely metaphysical reasons, and on the hypothesis that current physics is incomplete - a privileged but empirically undetectable reference frame that does not contradict the special theory of relativity, qua scientific theory. Such an empirically inaccessible inertial frame would do the job that presentists or threedimensionalists are after. The introduction of a privileged inertial frame for metaphysical 
reasons cannot be prohibited on physical reasons alone, even if it amounts to a very artificial tampering with a physical theory for purely metaphysical reasons that I would not recommend. What matters here, however, is that such a tampering per se does nothing to contribute to a deeper understanding of the current problems of time in physics (the origin of the arrow of time, the problem of establishing whether time exists at a fundamental level, the nature of cosmic time in its relation with becoming, whether time had a beginning, etc.).

In order to close in a more constructive fashion, I want to briefly propose a way to build a more fruitful relationship between physics and metaphysics by advancing the following interpretive project. In my view, interpreting physical theories could be regarded as a two stage project ${ }^{15}$ :

1) Coming up with a precise and exact ontology (in the sense of Bell) to associate to the language and formulas of physical theories;

2) Relating such ontology to the world of our experience.

These are the two inseparable tasks of metaphysicians and philosophers of physics, rendered indispensible by the frequent clash between the scientific (physical) image and the manifest image of the world (Sellars 1963). The question of the possibly conflicting relationship of the ontology of physics with that of our experience can arise only if the ontology of physics is taken at face value. It is only if the table is really made of atoms that the question of the relationship of the empty physical table with the hard and colored table of our experience can be posed at all (Eddington 1927). Both instrumentalism about physics and eliminationism about our conscious experience, however, are too easy way outs, and therefore no solutions to the problem of interpreting physical theories as articulated in 1) and 2). A quickly discussed example will illustrate the significance of the interpretive projects above.

As to 1): Finding out whether the universe becomes in time, for instance, is not an idle

\footnotetext{
${ }^{15}$ For more details, see Dorato (2010).
} 
metaphysical game, since it is linked to interpretations of the nature of time in Special Relativity, General Relativity and Quantum Gravity. For instance: what is the nature of cosmic time in cosmology? Does it allow some form of becoming of the universe that is objective? This question needs of course a precise explication of the intuitive notion of becoming.

The second point 2 is linked to a deeper understanding of the relationship between becoming and the various arrows of time in physics: if there is becoming, how is it linked to the other arrows of time? This problem it is linked to the need of relating the world of our experience, where time passes, to the world of physics in an explanatory fashion. For instance, suppose that the present is local and not global as the special theory of relativity seems to force us to acknowledge. It is possible to explain the illusion of a cosmic present via our neurophysiological perception of time?

As a sketch of an explanation, consider that we cannot perceive the present but only the past of events: we believe in the global nature of the present moment because of (1) the speed of light $c(300.000 \mathrm{~km} / \mathrm{s})$ and (2) the threshold time for perceiving the temporal succession of light signals (approximately 30ms). It follows that in a sphere of a radius of $9000 \mathrm{~km}$ (c times 30ms) we cannot perceive temporal succession, but only simultaneous events! If we want to create less superficial contacts between physics and metaphysics, we need to realize that the latter is an elaboration of the manifest image of the world, in which cognitive and neurophysiological sciences, beside conceptual apriori analysis, have an important role.

In a word, lest our philosophy becomes less and less in touch with real science, we need to stop worrying about problems that have no relevance for physics and rather try to form a synoptic view of the world in which the true task is connecting 1 ) with 2). This is only $a$ way to pursue metaphysics of science, of course: let thousands of flowers bloom. 
References

Broogard, Berit 2000: Presentist Four-Dimensionalism, IN: The Monist 83 (3), pp. 341-356.

Dieks, Dennis 2006: The Ontology of Spacetime Amsterdam: Elsevier.

Dolev, Yuval 2006: How to Square a Non-Localized Present with Special Relativity, IN: Dieks, Dennis 2006: pp. 177-190.

Dorato, Mauro 2006: The irrelevance of the presentism/eternalism debate for the ontology of Minkowski spacetime, in Dieks 2006, pp. 93-109.

Dorato, Mauro 2006a: Absolute becoming, relational becoming and the arrow of time: Some non conventional remarks on the relationship between physics and metaphysics, Studies in History and Philosophy of Modern Physics, Volume 37, Issue 3, September 2006, 559-576, reprinted in The Philosophy of Time, N. Oaklander (ed.), vol IV, London: Routledge, 2009, pp. 254-276.

Dorato, Mauro 2010, Physics and Metaphysics: Interaction or Autonomy?, IN: Claudio Calosi (ed), Physics and Metaphysics, HumanaMente, 13, Pisa: ETS, pp. 1-11, also available at http://www.humanamente.eu/

Eddington, Arthur 1927: The Nature of the Physical World [Gifford Lectures, University of Edinburgh, January-March 1927], reprinted Ann Arbor: University of Michigan Press, 1958.

Kim, Jaegwon., 1976: 'Events as Property Exemplifications', in M. Brand and D. Walton (eds.), Action Theory, Dordrecht: Reidel, pp. 159-77; reprinted in Events, pp. 117-35.

Mellor, David 1981: Real Time, Cambridge: Cambridge University Press.

Merricks, Trenton 1995: On the incompatibility of Enduring and Perduring Entities, IN: Mind 104, 523-531

Merricks, Trenton, 1999: Persistence, Parts and Presentism. In: Noûs, 33: pp. 421-38.

Miller, Kristie 2005: The Metaphysical Equivalence of Three and Four Dimensionalism, IN: Erkenntnis 62 (1): pp. 91 - 117.

Miller, Kristie 2009: Ought a fourdimensionalist to believe in temporal parts?, IN: Canadian Journal of Philosophy 39 (4): pp. 619-646.

Rea, Michael, 1998: Temporal Parts Unmotivated, IN: Philosophical Review, 107: 225-60.

Savitt, Steven 2000: There's No Time Like the Present (in Minkowski Spacetime) IN: Philosophy of Science 67 (Proceedings): S563-S574.

Savitt, Steven, 2006, Presentism and Eternalism in Perspective, IN: Dieks, Dennis 2006, pp. 111-127.

Sellars, Wilfrid, 1963: Science, Perception and Reality, London: Routledge \& Kegan Paul Ltd, ch.1.

Sider, Ted 2001: Fourdimensionalism. Ontology of persistence and time. Oxford: Oxford University Press. 